\title{
Fatty Acid Profiling in Rapeseed Mustard (Brassica species)
}

\author{
Gyanendra Kumar Rai ${ }^{1 *}$, Sreshti Bagati ${ }^{1}$, Pradeep Kumar Rai ${ }^{2}$, \\ Sunil Kumar Rai ${ }^{3}$ and Monika Singh ${ }^{4}$ \\ ${ }^{1}$ School of Biotechnology, Sher-e-Kashmir University of Agricultural Sciences and \\ Technology of Jammu 180009 (J\&K), India \\ ${ }^{2}$ ACHR, Udheywala, Sher-e-Kashmir University of Agricultural Sciences and Technology of \\ Jammu 180009 (J\&K), India \\ ${ }^{3}$ Division of Plant Breeding and Genetics, Sher-e-Kashmir University of Agricultural Sciences \\ and Technology of Jammu 180009 (J\&K), India \\ ${ }^{4}$ G.L. Bajaj Institute of Technology and Management, Greater Noida, \\ GB Nagar, UP - 201306, India \\ *Corresponding author
}

\begin{tabular}{|l|}
\hline Ke y w or d s \\
Brassica, Oil \\
quality, Fatty acids \\
\hline Article Info \\
\hline $\begin{array}{l}\text { Accepted: } \\
\text { 04 April } 2018 \\
\text { Available Online: } \\
\text { 10 May } 2018\end{array}$ \\
\hline
\end{tabular}

A B S T R A C T

An experiment was conducted during 2014-2015 to study the oil and fatty acids content in 26 genotypes of Brassica species. Significant differences $(p \leq 0.05)$ were observed among the genotypes for the oil quality, viz. oil content and fatty acids content. Oil content is in the range of $32.67-39.47 \%, 37.82-40.56 \%$ and $40.35-41.43 \%$ in Brassica juncea, Brassica napus and Brassica rapa seeds, respectively. The saturated fatty acid (Palmitic acid) content is in the range of 3.08-3.85, 3.70-5.15, 2.75-3.73\% in Brassica juncea, Brassica napus and Brassica rapa, respectively and oleic acid content is in the range of 0.80-48.70, 16.15-37.98 and 6.21-16.15 in Brassica juncea, Brassica napus and Brassica rapa, respectively. Significant variation $(\mathrm{p} \leq 0.05)$ was also observed for Linoleic acid content and linolenic acid. Linoleic acid content varied from 11.00- 45.30, 18.57- 26.93 and 14.08- 18.18\% in Brassica juncea, Brassica napus and Brassica rapa, respectively and linolenic acid content varied from 11.10- 26.72, 9.99- 17.23 and 9.82- $26.66 \%$ in Brassica juncea, Brassica napus and Brassica rapa, respectively. The Erucic acid, another important trait also differed significantly amongst the Brassica species genotypes being 0.80- 49.40, 10.04- 34.96 and 43.77- 49.99\%. The minimum Erucic acid content was recorded in Brassica juncea genotypes PM-24 (0.80\%) and significantly at par with PM21, PM-22, Pusa Karishma and Nov Gold, whereas maximum Erucic acid content were recorded in Pusa Bold (49.40\%), DGS-1(34.96\%) and RSPT-02 (49.99\%) in Brassica juncea, Brassica napus and Brassica rapa, respectively. Significant variability in fatty acids content were noted in rapeseed mustard. The present study can be utilized in the breeding programme to develop qualitative genotypes with higher oil content and yield

\section{Introduction}

Rapeseed mustard is the preferred source of vegetable oil occupies a premier place in the world among all the oilseed crops and is also used as animal fodder, manure, condiment and has various industrial implications. The fatty acid content varies among various members of the Brassicaceae family and is determined by factors like the type of species, variety and the environmental conditions to which it is subjected (Mekki, 2013). Brassica species are 
enriched in various saturated and unsaturated fatty acids. The saturated fatty acids (SFAs) includes Palmitic acid whereas, the unsaturated fatty acids are either monounsaturated (MUPAs) i.e. erucic acid and oleic acid or polyunsaturated fatty acids (PUFAs) such as omega-3- alpha- linolenic acid and omega-6- linoleic acid which are nutritionally important. The presence and absence of these fatty acids determine the nutritional quality of the edible oils (Bhattacharya et al., 2012). Higher amount of Palmitic acid in edible oil leads to increased serum cholesterol (Kumar et al., 2014). Erucic acid which forms about $50 \%$ of the fatty acid composition of mustard oil is considered to be anti-nutritional when present $<2 \%$ in the edible oil, whereas higher amount of erucic acid in mustard oil makes it industrially important (Sharafi et al., 2015). It has been reported that an ideal edible oil should comprise of low saturated fats $(<6 \%)$, high oleic acid $(>50 \%)$, moderate amounts of linoleic $(<40 \%)$ and low linolenic acid $(<14 \%)$ (Potts et al., 1999). In Indian rapeseed mustard varieties, the oil obtained has higher amounts of erucic acid (35.7-51.4\%) and low amounts of oleic acid (10-15\%) (Kaushik and Agnihotri, 2000; Chauhan et al., 2007) which out lies the International Standards. Therefore, for meeting the quality standards there is an immediate need to develop Brassica varieties with low as well as high levels of erucic acid that can be used for edible and commercial purposes, respectively. Apart from checking the levels of erucic acid, another important objective should be to increase the level of oleic and linoleic acid and to reduce the amount of linolenic acid in the edible oil (Robbelen, 1991). One important approach towards this is to develop Brassica germplasm having low undesirable fatty acids by transferring the potential genes, preferably from the wild species into the cultivated ones through efficient breeding programmes (Pospisil et al., 2007). For the development of the improved Brassica germplasm, comprehensive knowledge of the fatty acid composition of various Brassica species ( $B$. juncea, B. carinata, B. oleracea, B. nigra, and $B$. rapa) becomes a pre-requisite.

Keeping this in view, the present study was carried out with the aim of evaluating various Brassica juncea, Brassica rapa and Brassica napus varieties for their fatty acid composition and oil content as well as assessing the variation for these traits within the species. The information thus obtained will prove useful in breeding programmes directed towards improvement of oil content and fatty acid composition in Brassica.

\section{Materials and Methods}

\section{Plant materials}

The seeds of 26 Brassica species including Brassica juncea (14 varieties), Brassica napus (7 varieties) and Brassica rapa (5 varieties) were procured from various sources (Table 1). The procured seed material was cultivated at the experimental field of SKUAST- Jammu. Three rows of each genotype were planted and the recommended package practices and plant protection measures were followed. Seeds were harvested when the plants attained complete maturity. Harvested seeds were used for oil content and fatty acid analysis.

\section{Determination of oil content}

The oil content from the matured seeds was extracted in the soxhlet apparatus using petroleum ether as solvent for $6 \mathrm{~h}$ according to the AOCS method (AOCS, 1993). Seeds of different mustard varieties were dried at $40{ }^{\circ} \mathrm{C}$ for $4 \mathrm{~h}$ in an oven to reduce the moisture level to $4-5 \%$. The dried seeds were then thoroughly ground and mixed with ether for extracting the total oil content. Subsequently, ether was removed from the oil by rotary 
evaporator under pressure and the oil content was calculated from the weight of oil and seeds using the formula,

Oil content $(\%)=\frac{\text { Oil weight }}{\text { Seed weight }} \times 100$

\section{Fatty acid profiling}

The fatty acid profiling of the Brassica varieties was carried out using Gas- Liquid Chromatography (GLC). Fatty acid methyl esters (FAME) of oil sample from each variety were developed according to the method described by Goli et al., (Goli et al., 2008). Agilent $6890 \mathrm{~N}$ gas chromatography equipped with a Flame Ionization Detector (FID) was used for FAME analysis. The oven injector and detector temperatures were regulated at 230 and $250^{\circ} \mathrm{C}$, respectively. Ultra-pure nitrogen gas was used as carrier.

The peaks of FAME were analysed by comparing their retention time to that of the known standards which had been subjected to similar separation conditions. The amount of individual fatty acids was expressed as $\%$ of the total fatty acids.

\section{Results and Discussion}

\section{Total oil content (\%)}

The total oil content, range and mean values of 26 Brassica varieties is shown in Table 2. Among all the Brassica species cultivated in India, Brassica rapa is the richest oil bearing species followed by Brassica napus and Brassica juncea. The seed oil content among the genotypes varied from $32.67-39.47 \%$ in Brassica juncea, 37.82- $40.56 \%$ in Brassica napus and 40.35- $41.43 \%$ in Brassica rapa (Table 2). The results indicate that sufficient variation exists for oil content within the genotypes of various species studied. Existence of variation for seed oil content is the remarkable feature of Brassica oil seeds which makes them a potential resource for exploitation in future plant breeding programmes. The results obtained in the present study are in close agreement with the earlier findings by other researchers (Mukherjee and Kiewitt, 1984; Getinet et al., 1997; Rabiee et al., 2004; Wilson, 2004; Singh et al., 2014; Sharafi et al., 2015). These results indicate that the different genotypes studied can serve as a reservoir of potential genes that can be used for improvement of oil content in different species of Brassica genus via various plant breeding programmes.

\section{Fatty acid profiling}

Table 3 indicates the fatty acid composition of various Brassica genotypes studied. In the present study, the content of saturated fatty acid (SFA) i.e. Palmitic acid (C16:0) ranged between for Brassica juncea genotypes, 3.70$5.15 \%$ in Brassica napus genotypes and 2.75$3.73 \%$ in Brassica rapa genotypes.

The amount of the SFA within different Brassica species was found to be less than $7 \%$ which is considered to be suitable for human consumption (Table 3). Brassica oilseeds with higher amounts of SFA lead to health disorders like hypercholesterolemia in humans whereas; the species with high palmitic acid have potential applications in soap and chemical industries (Singh et al., 2014).

Various Brassica genotypes studied showed huge variation for the amount unsaturated fatty acids i.e. the MUFAs and the PUFAs comprising of oleic (C18:1), eicosenoic (C20:1) erucic (C22:1), linolenic (C18:3) and linoleic $(\mathrm{C} 18: 2)$ acids, respectively. Among the MUFAs, the amount of oleic acid in the Brassica genotypes ranged from 0.80- 48.70\% in B. juncea, $16.15-37.98 \%$ in B. napus, 6.21$16.15 \%$ in $B$. rapa (Table 3 ). 
Table.1 List of Brassica varieties used for evaluation of fatty acid composition and oil content

\begin{tabular}{|c|c|c|c|}
\hline $\begin{array}{l}\text { S. } \\
\text { No }\end{array}$ & Variety & Species & Source \\
\hline 1 & RSPR-03 & B. juncea & Division of Plant Breeding and Genetics, SKUAST-Jammu \\
\hline 2 & Kranti & B. juncea & Division of Plant Breeding and Genetics, SKUAST-Jammu \\
\hline 3 & Pusa Bold & B. juncea & Division of Plant Breeding and Genetics, SKUAST-Jammu \\
\hline 4 & RL-1359 & B. juncea & Division of Plant Breeding and Genetics, SKUAST-Jammu \\
\hline 5 & RSPR-01 & B. juncea & Division of Plant Breeding and Genetics, SKUAST-Jammu \\
\hline 6 & $\begin{array}{l}\text { NPJ-153 } \\
(\mathrm{MCN}-11-14)\end{array}$ & B. juncea & Division of Plant Breeding and Genetics, SKUAST-Jammu \\
\hline 7 & Nov Gold & B. juncea & Division of Plant Breeding and Genetics, SKUAST-Jammu \\
\hline 8 & NRCDR-2 & B. juncea & Division of Plant Breeding and Genetics, SKUAST-Jammu \\
\hline 9 & Varuna & B. juncea & BHU, Varanasi, UP \\
\hline 10 & Pusa Mahak & B. juncea & Division of Genetics, IARI, New Delhi \\
\hline 11 & PM-21 & B. juncea & Division of Genetics, IARI, New Delhi \\
\hline 12 & PM-22 & B. juncea & Division of Genetics, IARI, New Delhi \\
\hline 13 & PM-24 & B. juncea & Division of Genetics, IARI, New Delhi \\
\hline 14 & $\begin{array}{l}\text { Pusa } \\
\text { Karishma }\end{array}$ & B. juncea & Division of Genetics, IARI, New Delhi \\
\hline 15 & RSPN-28 & B. napus & Division of Plant Breeding and Genetics, SKUAST-Jammu \\
\hline 16 & RSPN-29 & B. napus & Division of Plant Breeding and Genetics, SKUAST-Jammu \\
\hline 17 & DGS-1 & B. napus & Division of Plant Breeding and Genetics, SKUAST-Jammu \\
\hline 18 & GSL-1 & B. napus & Division of Plant Breeding and Genetics, SKUAST-Jammu \\
\hline 19 & RSPN-25 & B. napus & Division of Plant Breeding and Genetics, SKUAST-Jammu \\
\hline 20 & $\begin{array}{l}\text { HNS-0901 } \\
(\mathrm{NCN}-11-2)\end{array}$ & B. napus & DRMR, Bharatpur, Rajasthan, India \\
\hline 21 & $\begin{array}{l}\text { GSL-101 } \\
\text { (NCN-11-8) }\end{array}$ & B. napus & DRMR, Bharatpur, Rajasthan, India \\
\hline 22 & $\begin{array}{l}\text { RMT-08-02 } \\
(\text { TCN-11-12) }\end{array}$ & B. rapa & DRMR, Bharatpur, Rajasthan, India \\
\hline 23 & $\begin{array}{l}\text { PT-303 } \\
(\mathrm{TCN}-11-15)\end{array}$ & B. rapa & DRMR, Bharatpur, Rajasthan, India \\
\hline 24 & $\begin{array}{l}\text { RH-0701 } \\
\text { (TCN-11-6) }\end{array}$ & B. rapa & DRMR, Bharatpur, Rajasthan, India \\
\hline 25 & RSPT-01 & B. rapa & Division of Plant Breeding and Genetics, SKUAST-Jammu \\
\hline 26 & RSPT-02 & B. rapa & Division of Plant Breeding and Genetics, SKUAST-Jammu \\
\hline
\end{tabular}


Table.2 Total oil content (\%) and glucosinolate content ( $\mu \mathrm{mol} / \mathrm{g}$ defatted seed meal) in various Brassica genotypes

\begin{tabular}{|c|c|c|}
\hline S. No & Variety & Oil Content (\%) \\
\hline \multicolumn{3}{|c|}{ Brassica juncea genotypes } \\
\hline 1 & RSPR-03 & 38.48 \\
\hline 2 & Kranti & 37.03 \\
\hline 3 & Pusa Bold & 38.60 \\
\hline 4 & Varuna & 37.43 \\
\hline 5 & RSPR-01 & 37.74 \\
\hline 6 & RL-1359 & 38.63 \\
\hline 7 & Pusa Mahak & 38.33 \\
\hline 8 & NPJ-153 (MCN-11-14) & 39.18 \\
\hline 9 & PM-21 & 32.67 \\
\hline 10 & PM-22 & 33.19 \\
\hline 11 & PM-24 & 39.47 \\
\hline 12 & Pusa Karishma & 35.20 \\
\hline 13 & Nov Gold & 38.12 \\
\hline \multirow[t]{3}{*}{14} & NRCDR-2 & 38.96 \\
\hline & Mean & 37.36 \\
\hline & Range & 32.67- 39.47 \\
\hline \multicolumn{3}{|c|}{ Brassica napus genotypes } \\
\hline 15 & RSPN-28 & 39.70 \\
\hline 16 & RSPN-29 & 39.33 \\
\hline 17 & DGS-1 & 40.03 \\
\hline 18 & GSL-1 & 39.82 \\
\hline 19 & RSPN-25 & 39.04 \\
\hline 20 & HNS-0901 (NCN-11-2) & 40.56 \\
\hline \multirow[t]{3}{*}{21} & GSL-101 (NCN-11-8) & 37.82 \\
\hline & Mean & 39.47 \\
\hline & Range & 37.82- 40.56 \\
\hline \multicolumn{3}{|c|}{ Brassica rapa genotypes } \\
\hline 22 & RSPT-01 & 41.42 \\
\hline 23 & RSPT-02 & 40.80 \\
\hline 24 & RMT-08-02 (TCN-11-12) & 40.35 \\
\hline 25 & PT-303 (TCN-11-15) & 41.43 \\
\hline \multirow[t]{3}{*}{26} & RH-O701 (TCN-11-6) & 40.52 \\
\hline & Mean & 40.90 \\
\hline & Range & $40.35-41.43$ \\
\hline
\end{tabular}


Table.3 Fatty acid composition of various Brassica varieties

\begin{tabular}{|c|c|c|c|c|c|c|c|}
\hline \multirow[b]{2}{*}{ S. NO } & \multirow[b]{2}{*}{ Varieties } & \multirow{2}{*}{$\begin{array}{l}\text { Saturated Fatty acid } \\
(\%) \\
\text { Palmitic acid }\end{array}$} & \multicolumn{5}{|c|}{ Unsaturated Fatty acids (\%) } \\
\hline & & & Oleic acid & Linoleic acid & Linolenic acid & Eicosenoic acid & Erucic acid \\
\hline \multicolumn{8}{|c|}{ Brassica juncea genotypes } \\
\hline 1 & RSPR-03 & 3.44 & 10.35 & 20.77 & 24.08 & 1.11 & 40.21 \\
\hline 2 & Kranti & 3.85 & 7.34 & 18.57 & 24.40 & 0.00 & 45.83 \\
\hline 3 & Pusa Bold & 3.68 & 7.10 & 16.41 & 22.32 & 1.05 & 49.40 \\
\hline 4 & Varuna & 3.23 & 10.92 & 18.50 & 20.94 & 1.26 & 45.13 \\
\hline 5 & RSPR-01 & 3.59 & 8.24 & 18.17 & 26.72 & 0.00 & 43.24 \\
\hline 6 & RL-1359 & 3.47 & 8.67 & 17.41 & 24.03 & 0.00 & 46.39 \\
\hline 7 & Pusa Mahak & 3.08 & 7.60 & 15.33 & 24.44 & 1.04 & 48.48 \\
\hline 8 & NPJ-153 (MCN-11-14) & 3.30 & 8.19 & 18.34 & 23.06 & 0.00 & 47.09 \\
\hline 9 & PM-21 & - & 0.90 & 39.80 & 13.60 & 29.50 & 0.90 \\
\hline 10 & PM-22 & - & 1.00 & 45.30 & 11.10 & 34.50 & 1.00 \\
\hline 11 & PM-24 & - & 0.80 & 34.20 & 15.20 & 34.90 & 0.80 \\
\hline 12 & Pusa Karishma & - & 0.90 & 37.60 & 18.80 & 31.30 & 0.90 \\
\hline 13 & Nov Gold & - & 48.70 & 11.00 & 17.80 & 14.80 & 48.70 \\
\hline \multirow[t]{3}{*}{14} & NRCDR-2 & - & 47.40 & 11.50 & 12.00 & 15.50 & 47.40 \\
\hline & Mean & - & 12.01 & 23.06 & 19.89 & 11.78 & 33.25 \\
\hline & Range & 3.08-3.85 & $0.80-48.70$ & $11.00-45.30$ & 11.10- 26.72 & $0.00-34.90$ & $0.80-49.40$ \\
\hline \multicolumn{8}{|c|}{ Brassica napus genotypes } \\
\hline 1 & RSPN-28 & 4.87 & 19.45 & 21.67 & 11.20 & 14.72 & 28.05 \\
\hline 2 & RSPN-29 & 4.14 & 24.13 & 20.71 & 11.24 & 15.94 & 23.80 \\
\hline 3 & DGS-1 & 4.32 & 16.15 & 18.57 & 9.99 & 15.97 & 34.96 \\
\hline 4 & GSL-1 & 4.71 & 21.06 & 18.83 & 10.58 & 13.64 & 31.15 \\
\hline 5 & RSPN-25 & 5.15 & 20.76 & 19.87 & 10.30 & 15.58 & 28.29 \\
\hline 6 & HNS-0901 (NCN-11-2) & 4.36 & 34.68 & 23.01 & 14.31 & 12.58 & 10.04 \\
\hline \multirow[t]{3}{*}{7} & GSL-101 (NCN-11-8) & 3.70 & 37.98 & 26.93 & 17.23 & 0.00 & 15.01 \\
\hline & Mean & 4.46 & 24.89 & 21.37 & 12.12 & 12.63 & 24.47 \\
\hline & Range & $3.70-5.15$ & 16.15- 37.98 & 18.57- 26.93 & 9.99- 17.23 & 0.00- 15.97 & 10.04- 34.96 \\
\hline \multicolumn{8}{|c|}{ Brassica rapa genotypes } \\
\hline 1 & RSPT-01 & 2.75 & 12.67 & 16.82 & 9.97 & 10.13 & 47.63 \\
\hline 2 & RSPT-02 & 2.99 & 10.17 & 15.18 & 10.75 & 10.87 & 49.99 \\
\hline 3 & RMT-08-02 (TCN-11-12) & 3.73 & 11.73 & 18.18 & 20.89 & 1.67 & 43.77 \\
\hline 4 & PT-303 (TCN-11-15) & 3.00 & 16.15 & 16.06 & 9.82 & 10.85 & 44.10 \\
\hline \multirow[t]{3}{*}{5} & RH-0701 (TCN-11-6) & 3.11 & 6.21 & 14.08 & 26.66 & 5.13 & 44.79 \\
\hline & Mean & 3.12 & 11.39 & 16.06 & 15.62 & 7.73 & 46.06 \\
\hline & Range & 2.75- 3.73 & $6.21-16.15$ & 14.08- 18.18 & $9.82-26.66$ & $1.67-10.87$ & 43.77- 49.99 \\
\hline
\end{tabular}


The results obtained in the study are in agreement with those obtained by Chhokar et al., 2008; Singh et al., 2014; Sharafi et al., 2015. Higher amounts of oleic acid are considered to be of nutritive value for human consumption as it increases the level of Highdensity lipoproteins (HDLs) and decreases the level of low- density lipoproteins (LDLs) in blood (Chang and Huang, 1998). Moreover, high oleic acid content in seed oil makes it more thermo stable, thereby making it more suitable for cooking purposes (Appelqvist, 1968). Apart from playing an important role in increasing the efficiency of cooking oil, oleic acid makes the seed oil more suitable for industrial purposes as well (Wilson, 2004). Another important MUFA is the erucic acid which is known to be antinutritional and undesirable for human consumption when present in higher amounts in edible oil.

The erucic acid content in Brassica species varied from $0.80-49.40 \%$ in $B$. juncea varieties, $10.04-34.96 \%$ in $B$. napus varieties and 43.77- 49.99\% in B.rapa varieties (Table 3 ). Higher erucic acid in cooking oil hampers the myocardial conductance in humans and leads to increased blood cholesterol levels (Bozzini et al., 2007; Sinha et al., 2007). Several genotypes in the present study which showed higher levels of erucic acid will be of utmost importance for various industries. Oil rich in erucic acid is used as raw material in plastic, tannery, cosmetic, polyster and detergent industries (Rakow and Raney, 2003, Coonrod et al., 2008). At present, when the Brassica breeding programmes are focused towards the development of zero erucic lines for nutritional purpose the genotypes Pus Karishma, PM- 21 and PM- 24 with low erucic acid will be of huge importance. Various Brassica rapa genotypes in the present study have erucic acid $<40 \%$ which is in context to the previous results reported by Appelqvist, 1971; Velasco et al., 1998; Chhokar et al., 2008; Sharafi et al., 2015.
The PUFAs i.e. linoleic and linolenic acids should be present in lower levels in the cooking oil. The amount of linoleic and linolenic acids varied between 11.00-45.30\%, 11.10- 26.72\%; 18.57- 26.93\%, 9.99- $17.23 \%$ and $14.08-18.18 \%, 9.82-26.66 \%$ in $B$. juncea, $B$. napus and $B$. rapa genotypes, respectively (Table 3 ). Similar results have been reported by Peiretti and Meineri, 2007; Singh et al., 2014; Sharafi et al., 2015. These PUFAs are known to be the precursors of long chain fatty acids involved in the synthesis of metabolically important compounds like prostaglandins. Linoleic acid which is an essential fatty acid isn't synthesized by human body and hence must be obtained from diet. It has been reported high linoleic acid levels in edible oil reduces blood cholesterol and prevents atherosclerosis (Ghafoorunissa, 1994). Although linolenic acid is another essential fatty acid, yet its presence in the oil may lead to rancidity and off flavor (Sharafi et al., 2015).

According to the present study, the Brassica varieties having low levels of erucic acid and high levels of linoleic acids can be used in Brassica breeding programmes directed towards enhancing the quality of oil for nutritional and industrial applications.

The present research work was conducted to assess genotypes for qualitative parameters. Most of Brassica varieties cultivated in our country containing high level of erucic acid have deleterious effects on human health. Efforts are being made to develop varieties which contain less than 2 per cent erucic acid through breeding programmes. Erucic acid is a mono-unsaturated omega-9 fatty acid, denoted C22: $1 \mathrm{w}-9$. It is a potent inhibitor of saturated very long chain fatty acids, erucic acid inhibits the synthesis of the long chain fatty acids. Since 1970, there has been a growing awareness about the nutritional quality of the oil and meal and this has shifted 
the emphasis towards breeding for high yield and quality traits in rapeseed mustard in order to bridge the gap between production and consumption. This strategy however, proved to be of little help to overcome the deficit of edible oil. The Indian rapeseed and mustard cultivars have high amounts of nutritionally undesired components, erucic acid and glucosinolates. Therefore, there is an urgent need to develop new varieties, containing low levels of erucic acid and glucosinolates. The data revealed that genotypes i.e. PM-21, PM22, PM-24, Pusa Karishma and Nov Gold have low erucic acid content making them fit for commercial cultivation and use for introgression of low erucic acid traits in higher yielding cultivars. The information related to the significant variability of the fatty acid content in the various Brassica species observed in the present study can be utilized in the breeding programmes to develop genotypes with higher qualitative potential.

\section{Acknowledgement}

The authors are grateful to Department of Biotechnology, New Delhi for financial support of this work (Project sanction order No. BT/PR7885/AGII/106/919/2013).

\section{References}

Al-Gendy AA, El-gindi OD, Hafez AS, Ateya AM (2010). Glucosinolates, volatile constituents and biological activities of Erysimum corinthium Boiss. (Brassicaceae). Food Chem 118: 519524.

AOCS (1993). Official Methods and Recommended Practices; The American Oil Chemists Society: Champaign, IL, pp 113-168.

Appelqvist LA (1968). Lipids in Cruciferae. III. Fatty acid composition of diploid and tetraploid seeds of Brassica campestris and Sinapis alba grown under two climatic extremes. Physiol Plantarum 21:615-625.

Appelqvist LE (1971). Lipids in Cruciferae: VIII. The fatty acid composition of seeds of some wild or partially domesticated species. Journal of the American Oil Chemists' Society 48: 740-744.

Bala M, Kumar S, Singh L (2011). Antioxidant potential of rapeseedmustard seed meal extracts. Indian $J$ Agric Biochem 24: 55-59.

Bhattacharya S, Sinha S, Dey P, Das M, Maiti MK (2012). Production of nutritionally desirable fatty acids in seed oil of Indian mustard (Brassica juncea L.) by metabolic engineering. Phytochem Rev 11:197-209.

Blazevic I, Mastelic J (2009). Glucosinolate degradation products and other bound and free volatiles in the leaves and roots of radish (Raphanus sativus L.). Food Chem. 113: 96-102.

Bozzini A, Calcagno F, Soare T (2007) "Sincron", a new Brassica carinata cultivar for biodiesel production. Helia 46:207-214.

Chang NW, Huang PC (1998). Effects of the ratio of polyunsaturated and monounsaturated fatty acids on rat plasma and liver lipid concentration. Lipids 33:481-487.

Chauhan JS, Bhadauria VPS, Singh M, Singh KH, Kumar A (2007). Quality characteristics and their interrelationship in Indian rapeseedmustard (Brassica $\mathrm{sp}$ ) varieties. Indian J Agric Sci 77: 616-620.

Chhokar V, Beniwal V, Kumar A, Rana JS (2008). Lipid content and fatty acid composition of mustard (Brassica iuncea. L) during seed development. The Asian Journal of Experimental Chemistry 3(1\&2): 6-9. 
Coonrod D, Brick MA, Byrne PF, Debonte L, Chen Z (2008). Inheritance of long chain fatty acid content in rapeseed (Brassica napus L.). Euphytica 164: 583-592.

Getinet A, Rakow G, Raney JP, Downey RK (1997). The inheritance of erucic acid content in Ethiopian mustard. Canadian Journal of Plant Science 77: 33-41.

Ghafoorunissa (1994). Dietary fats/oils and heart diseases. In Sustainability in Oil Seeds; Prasad, M.V.R., Eds.; Indian Soc Oil Seed Res; Hyderabad, pp. 486-490.

Goli SAH, Sahri MM, Kadivar M (2008). Enzymatic inter esterification of structured lipids containing conjugated linoleic acid with palm stearin for possible margarine production. European Journal of Lipid Science and Technology 110: 1102-1108.

Ildiko SG, Klara KA, Marianna TM, Agnes B, Zsuzsanna MB, Balint C (2006). The effect of radio frequency heat treatment on nutritional and colloid-chemical properties of different white mustard (Sinapis alba L.) varieties. Innov Food Sci Emerg 7:74-79.

Kaushik N and Agnihotri A (2000). GLC analysis of Indian rapeseed-mustard to study the variability of fatty acid composition. Biochemical Society T 28: 581-3.

Kumar A (2014). Challenge of edible oils: Can Brassicas deliver? Journal of Oilseed Brassica 5 (2): 83-86.

Kumar S, Chauhan JS, Kumar A (2010). Screening for erucic acid and glucosinolate content in rapeseedmustard seeds using near infrared reflectance spectroscopy. J Food Sci Technol 47(6): 690-692.

Mekki BB (2013). Yield and quality traits of some canola varieties grown in newly reclaimed sandy soils in Egypt. World Applied Sciences Journal 25 (2): 258263.
Mukherjee KD, Kiewitt I (1984). Changes in fatty acid composition of lipid classes in developing mustard seed. Phytochemistry 23:349-352.

Peiretti PG, Meineri G (2007). Fatty acids, chemical composition and organic matter digestibility of seeds and vegetative parts of false flax (Camelina sativa L.) after different lengths of growth. Anim Feed Sci Technol 133: 341-350.

Pospisil M, Skevin D, Mustapic, Nakic SN, Butorac J, Matijevic D (2007). Fatty acid composition in oil of recent rapeseed hybrids and 00-cultivars. Agriculture Conventions Science 72: 187-193.

Potts DA, Rakow GW, Males DR (1999). Canola-quality Brassica juncea, a new oilseed crop for the Canadian prairies. In Proc: Xth International Rapeseed Congress, September 26-29, Canberra, Australia.

Rabiee M, Karimi MM, Safa F (2004). Effect of planting dates on grain yield and agronomical characters of rapeseed cultivars as a second crop after rice at Kouchesfahan. Iranian Journal of Agricultural Science 35: 177-187.

Rakow G, Raney G (2003). In Present Status and Future Perspectives of Breeding for Seed Quality in Brassica Oilseed Crops, Proceeding of the 11th International Rapeseed Congress, Copenhagen, Denmark.

Robbelen G (1991). Rapeseed in a changing world: plant production potential. In: GCIRC (Ed), Proceedings of the 8th International Rapeseed Congress, Saskatoon, Canada, 9-11 July 1991, pp. 29-38, GCIRC, Saskatoon, Canada.

Sharafi Y, Majidi MM, Goli SAH, Rashidi F (2015). Oil content and fatty acids composition in Brassica species. International Journal of Food Properties 18 (10): 2145-2154. 
Shears SB (2001). Assesssing the omnipotence of inositol hexakisphosphate. Cell Signal 13:151158.

Singh BK, Bala M, Rai PK (2014). Fatty acid composition and seed meal characteristics of Brassica and allied genera. Natl. Acad. Sci. Lett. 37(3): 219-226.

Sinha S, Jha JK, Maiti MK, Basu A, Mukhopadhyay UK, Sen SK (2007). Metabolic engineering of fatty acid biosynthesis in Indian mustard (Brassica juncea) improves nutritional quality of seed oil. Plant Biotechnol Rep 1: 185-197.

Thies W (1982). Complex-formation between glucosinolates and tetrachloropalladate (II) and its utilization in plant breeding. Fette. Seifen. Anstrichm 84: 338-342.
Thompson LU (1990). Phytates in canola/ rapeseed. In: Shahidi F (ed) Canola and rapeseed production. Chemistry, Nutrition and Processing Technology, New York.

Velasco L, Goffman FD, Becker HC (1998). Variability for the fatty acid composition of the seed oil in a germplasm collection of the genus Brassica. Genet Res Crop Evol 45: 371382.

Wilson RF (2004) Seed composition. In: Boerma HR, Specht JE (eds) Soybeans: improvement, production and uses. American Society of Agronomy, Madison.

Winde I, Wittstock, U (2011). Insect herbivore counters adaptions to the plant glucosinolate-myrosinase system. Phytochem 72: 1566-1575.

\section{How to cite this article:}

Gyanendra Kumar Rai, Sreshti Bagati, Pradeep Kumar Rai, Sunil Kumar Rai and Monika Singh. 2018. Fatty Acid Profiling in Rapeseed Mustard (Brassica species). Int.J.Curr.Microbiol.App.Sci. 7(05): 148-157. doi: https://doi.org/10.20546/ijcmas.2018.705.019 